\title{
Seasonal evolution of snow permeability under equi-temperature and temperature-gradient conditions
}

\author{
F. Domine ${ }^{1,2, *}$, S. Morin ${ }^{3, *}$, E. Brun ${ }^{4}$, M. Lafaysse ${ }^{3}$, and C. M. Carmagnola ${ }^{3}$ \\ ${ }^{1}$ Takuvik Joint International Laboratory, Université Laval (Canada) and CNRS-INSU (France), UMI3376, Pavillon Alexandre \\ Vachon, 1045 avenue de La Médecine, Québec, QC, G1V 0A6, Canada \\ ${ }^{2}$ Department of Chemistry, Université Laval, Québec, QC, Canada \\ ${ }^{3}$ Météo-France - CNRS, CNRM-GAME UMR3589, CEN, Grenoble, France \\ ${ }^{4}$ Météo-France - CNRS, CNRM-GAME UMR3589, Toulouse, France \\ ${ }^{*}$ These authors contributed equally to this work.
}

Correspondence to: F. Domine (florent.domine@gmail.com)

Received: 26 April 2013 - Published in The Cryosphere Discuss.: 17 June 2013

Revised: 29 October 2013 - Accepted: 25 November 2013 - Published: 18 December 2013

\begin{abstract}
The permeability $(K)$ of snow to air flow affects the transfer of energy, water vapor and chemical species between the snow and the atmosphere. Yet today little is known about the temporal evolution of snow permeability as a function of metamorphic regime. Furthermore, our ability to simulate snow permeability over the seasonal evolution of a snowpack has not been tested. Here we have measured the evolution of snow permeability in a subarctic snowpack subject to high temperature-gradient (TG) metamorphism. We have also measured the evolution of the same snowpack deposited over tables so that it evolved in the equi-temperature (ET) regime. Permeability varies in the range $31 \times 10^{-10}$ (ET regime) to $650 \times 10^{-10} \mathrm{~m}^{2}$ (TG regime). Permeability increases over time in TG conditions and decreases under ET conditions. Using measurements of density $\rho$ and of specific surface area (SSA), from which the equivalent sphere radius $r$ is determined, we show that the equation linking SSA, density $\rho$ and permeability, $K=3.0 r^{2} e^{(-0.013 \rho)}$ (with $K$ in $\mathrm{m}^{2}, r$ in $\mathrm{m}$ and $\rho$ in $\mathrm{kg} \mathrm{m}^{-3}$ ) obtained in a previous study adequately predicts permeability values. The detailed snowpack model Crocus is used to simulate the physical properties of the TG and ET snowpacks. For the most part, all variables are well reproduced. Simulated permeabilities are up to a factor of two greater than measurements for depth hoar layers, which we attribute to snow microstructure and its aerodynamic properties. Finally, the large difference in permeabilities between ET and TG metamorphic regimes will impact atmosphere-snow energy and mass exchanges. These
\end{abstract}

effects deserve consideration in predicting the effect of climate change on snow properties and snow-atmosphere interactions.

\section{Introduction}

Snow is a porous medium through which air can circulate and transfer mass and energy. Circulation can be induced over flat snow surfaces by processes such as turbulence (Sokratov and Sato, 2000; Clifton et al., 2008) and over rough surfaces by wind pumping (Colbeck, 1989). One noteworthy consequence of these processes is the deposition of atmospheric particles such as sulfate and sea salt to snow, affecting the chemical composition of snow (Cunningham and Waddington, 1993; Domine et al., 2004; Harder et al., 1996). Examples of the importance of understanding these chemical changes include the interpretation of ice core analyses in terms of past atmospheric composition (Legrand and Mayewski, 1997) and the quantification of the sources of seasalt-derived bromine that destroys tropospheric ozone in polar regions (Simpson et al., 2005; Bottenheim et al., 2009; Spicer et al., 2002). Another consequence is that air circulation modifies the temperature and the water vapor budget of the snow in the top few centimeters, a process that should be accounted for in order to properly model surface snow energy and mass balance in the presence of moderate to strong winds (Reimer, 1980; Albert and Hardy, 1995; Sokratov and Sato, 
2000; Albert and Shultz, 2002; Clifton et al., 2008; Bartlett and Lehning, 2011).

Quantification of air flow through snow requires the knowledge of its intrinsic permeability $K$, as defined by Darcy's law:

$v=-\frac{K}{\eta} \frac{\partial P}{\partial x}$,

where $v$ is the air velocity, $\eta$ its dynamic viscosity and $\partial P / \partial x$ is the pressure gradient along the direction of air flow. Snow permeability measurements have been made on seasonal and glacier snow (Shimizu, 1970; Albert and Perron, 2000; Albert and Shultz, 2002; Albert et al., 2000; Sommerfeld and Rocchio, 1993; Conway and Abrahamson, 1984; Arakawa et al., 2009), and the ranges of values for each snow type have been compiled by Domine et al. (2008), who show values as low as $1 \times 10^{-10} \mathrm{~m}^{2}$ for ice layers and as high as $800 \times 10^{-10} \mathrm{~m}^{2}$ for depth hoar. Given this wide range of permeability values, it appears worthwhile to be able to calculate properly this variable in snow models, as this is important for both applications mentioned above.

Equations have been proposed that relate permeability to other snow physical variables (Shimizu, 1970; Freitag et al., 2002; Arakawa et al., 2009; Calonne et al., 2012). The relationship provided by Shimizu (1970), which relates permeability $K\left(\right.$ in $\left.\mathrm{m}^{2}\right)$ to the visually determined grain radius $r_{\text {vis }}$ and snow density $\rho$ (in units of $\mathrm{m}$ and $\mathrm{kg} \mathrm{m}^{-3}$, respectively), has probably been the most widely used:

$K=0.308 r_{\text {vis }}^{2} e^{(-0.0078 \rho)}$,

even though it was obtained on a limited number of snow types so that its general validity has been questioned (Jordan et al., 1999). More recent works (Calonne et al., 2012; Courville et al., 2010), based on calculations from tomographic images of snow samples, offer hope of progress. Calonne et al. (2012) proposed

$K=3.0 r^{2} e^{(-0.013 \rho)}$,

with $K$ in $\mathrm{m}^{2}, r$ in $\mathrm{m}$ and $\rho$ in $\mathrm{kg} \mathrm{m}^{-3}$ and where equivalent sphere radius $r$ was determined from the specific surface area (SSA) following:

$r=3 /\left(\rho_{\text {ice }} \mathrm{SSA}\right)$,

with $\rho_{\text {ice }}$ the density of ice. Eq. (3) significantly differs from Eq. (2) for low density snows. Intuitively, the form of Eqs. (2) and (3) is easy to understand: increasing density reduces porosity and therefore pore size, thus reducing air flow. Increasing SSA (i.e. decreasing $r$ ) increases friction on surfaces, also impeding air flow.

Despite these interesting developments, little is still known about the variations of permeability during snow metamorphism. Given the relationship between $K$, SSA and $\rho$, and the fact that SSA and $\rho$ generally decrease and increase, respectively, with time during snow metamorphism, it is not possible to predict the rate of variation of snow permeability in a given snow layer without knowing precisely the time evolution of both SSA and $\rho$. How $K$ evolves with time depending on the metamorphic regime is thus an unanswered question. This work pursues four major objectives: (a) provide an independent evaluation of Eq. (3) against in situ collocated measurements of $K$, SSA and $\rho$. Measurements of the latter two variables have been presented by Taillandier et al. (2006) and Taillandier et al. (2007). Collocated permeability measurements are reported for the first time here. (b) Monitor the evolution of snow permeability in a cold subarctic snowpack evolving under a high temperature gradient conducive to depth hoar formation. (c) Extend the scope and range of validity of the study by also monitoring a manipulated snowpack evolving under low temperature gradient conditions leading mostly to the formation of rounded grains. (d) Test our ability to model the evolution of permeability using SSA and density outputs from the detailed snowpack model Crocus (Brun et al., 1992; Vionnet et al., 2012) using Eq. (3). The intrinsic permeability of snow is not only important for air circulation but also liquid water movement through snow, which makes our study equally relevant for scientific developments in this research area (e.g. Wever et al., 2013).

\section{Methods}

\subsection{Experimental methods}

The study was conducted at the Large Animal Research Station (LARS, $64^{\circ} 52^{\prime} \mathrm{N}-147^{\circ} 44^{\prime} \mathrm{W}, 210 \mathrm{~m}$ a.s.l.) of the University of Alaska Fairbanks during the 2003-2004 winter, as already detailed by Taillandier et al. (2006). The site was in a clearing with generally low wind conditions so that the snowpack was laterally homogeneous, allowing meaningful repetitive sampling of snow at several stratigraphic levels throughout the season. The climate is subarctic, with air temperature occasionally dropping below $-40{ }^{\circ} \mathrm{C}$. The low air temperatures, combined with a shallow snowpack (maximum thickness of $54 \mathrm{~cm}$ in late March), induce a high temperature gradient in the snowpack, which almost entirely transforms into depth hoar. The maximum value of the temperature gradient was $198 \mathrm{Km}^{-1}$, decreasing to $20 \mathrm{Km}^{-1}$ in the spring as the snow depth increased (Taillandier et al., 2006). This snowpack was therefore used to study permeability evolution under temperature gradient metamorphism, hereafter TG conditions following the terminology of Sommerfeld and LaChapelle (1970). Because we felt that studying just one snowpack type may not be sufficient to test SSAdensity-permeability relationships, we also attempted to reproduce a snowpack evolving under low temperature gradient conditions (equi-temperature, or ET metamorphism after 


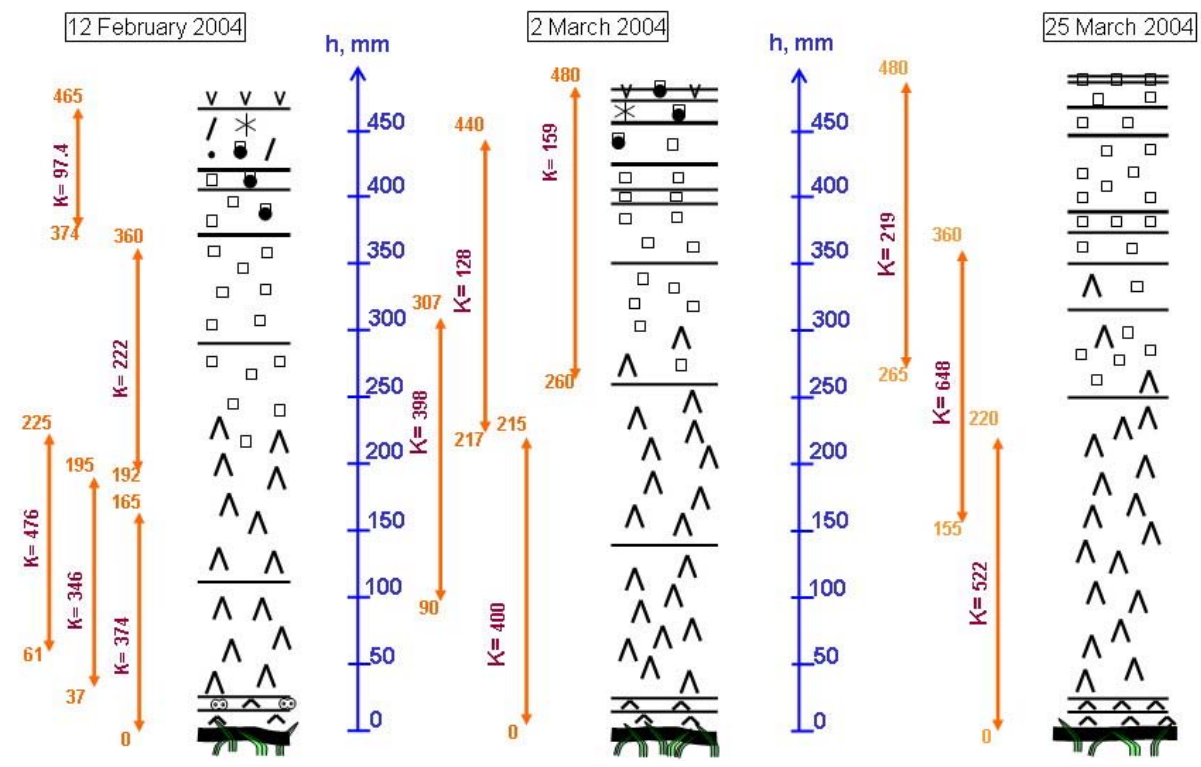

Fig. 1. Stratigraphy and permeability $K$, in units of $10^{-10} \mathrm{~m}^{2}$, of snow cores sampled at the levels indicated by the orange arrows, for the ground snowpack. Snow cores were about $20 \mathrm{~cm}$ tall, and the heights of their bases and tops are shown (in mm for better precision) at each end of the orange arrows. Symbols are from the International Classification of Seasonal Snow on the Ground (Fierz et al., 2009).

Sommerfeld and LaChapelle, 1970), by suppressing the temperature gradient in the snowpack. This was realized by allowing the snow to deposit onto three tables $1.5 \times 3 \mathrm{~m}$, so that air circulation under them prevented the durable establishment of any significant temperature gradient (Taillandier et al., 2007). Alternating temperature gradients could take place in surface snow on the tables, leading to the formation of crystals having shapes similar to those produced by ET metamorphism (Pinzer and Schneebeli, 2009). However, the latitude of our site implied that the energy deposited onto the snowpack by solar radiation was very small throughout most of the winter. Temperature measurements in the snow (Taillandier et al., 2006) showed that significant alternating temperature gradients did not establish themselves until early March, so that the metamorphic regime was indeed essentially ET. Of course, the base of the snowpack reached very low temperatures approaching $-40^{\circ} \mathrm{C}$, whereas natural ET snowpacks are generally of the maritime type and therefore at warmer temperatures. Hence, this snowpack is not a perfect substitute for a natural ET snowpack, but the crystal shapes nevertheless presented excellent similarities with those of real ET snowpack and we believe that it presents interest to test the models and relationships used here in more depth. In addition, it may represent some of the natural conditions encountered in snow lying on ice sheets (Greenland, Antarctica).

The tables consisted of a wooden frame over which a thin sheet of corrugated steel was screwed. A $40 \mu \mathrm{m}$-thick polyethylene sheet was placed over the metal. This setup allows us to neglect the thermal inertia of the surface over which the table snowpack formed and to approximate the temperature at the base of the snowpack with the air temperature in calculations. The edges of the snow on the tables were protected from wind erosion by polyethylene sheets. Wind speed was almost always low, as detailed in Taillandier et al. (2006), see their Fig. 1. The typical wind speed at $3 \mathrm{~m}$ height was below $2 \mathrm{~m} \mathrm{~s}^{-1}$ and the maximum wind speed during the study was $4.5 \mathrm{~m} \mathrm{~s}^{-1}$, reached in early January. Such speeds were never strong enough to cause saltation of surface snow. However, the table snow was more exposed and even with the protective sheet, a small fraction of the table snow was eroded by wind in early January. Other erosion episodes may have taken place but were not observed. SSA and density measurements, already reported by (Taillandier et al., 2006) started in November and ended in April. Permeability measurements were carried out on 4 February, 2 March and 25 March on the natural snowpack on the ground (hereafter: ground snowpack) and on 16 February and 9 March on the table snowpack, producing five vertical profiles of combined snow properties including SSA, density and permeability, totaling 18 snow permeability measurements (12 on ground, 6 on tables).

SSA was measured using the $\mathrm{CH}_{4}$ adsorption method (Domine et al., 2007b). Density was measured with density cutters, using a $500 \mathrm{~cm}^{3}$ Plexiglas tube $5 \mathrm{~cm}$ in inner diameter. Permeability was measured with the US Army Cold Regions Research and Engineering Laboratory (CRREL) permeameter (Jordan et al., 1999). Briefly, a vertical snow core $10 \mathrm{~cm}$ in diameter and 10 to $25 \mathrm{~cm}$ in height was sampled. No horizontal core could be sampled, as the weak depth hoar immediately fell apart and the structure was irremediably modified. The permeameter was installed on a table 
next to the sampling site, so that no sample transport was required. A pump was used to establish air flow through the snow and a differential manometer was used to measure the pressure difference between the upstream and downstream parts of the snow core. A double cylinder head minimized flow at the edge of the sample (Shimizu, 1970). A valve allowed the regulation of the flow rate, and about 10 flow rates were used for each sample. Plotting the pressure difference as a function of flow rate yielded a linear plot whose slope was used to determine $K$ according to Eq. (1). Sometimes, deviations from linearity were observed at high flow rates (typically $>0.08 \mathrm{~m} \mathrm{~s}^{-1}$, as detailed in Jordan et al., 1999) because these were beyond the validity range of Eq. (1). Those data were discarded.

Air temperature, humidity, and wind speed were measured on-site during the field experiment from 28 October 2003 to 22 April 2004, and are reported by Taillandier et al. (2006) and Jacobi et al. (2010).

\subsection{Numerical simulations methods}

The time evolution of the vertical profile of the physical properties of the snowpack was simulated using the detailed snowpack scheme Crocus (Brun et al., 1992; Vionnet et al., 2012), of the ISBA land surface model within the modeling platform SURFEX (Masson et al., 2013). Subsequently, we refer to the snow model as Crocus. Its main improvement over the previous stand-alone version of Crocus (Brun et al., 1992; Jacobi et al., 2010) is that the snowpack scheme is fully coupled to a soil scheme accounting for thermal diffusion (including phase-change effects) in the soil underlying the snowpack (Decharme et al., 2011). For this study, 20 soil levels were used with lower depths of 1, 3, 6, 10, 20, 30, 45, $60,80,100,125,150,200,250,300,400,500,650,800$ and $1000 \mathrm{~cm}$ below the ground (soil) surface. The soil composition was arbitrarily set to $1 / 3$ clay and $2 / 3$ sand, consistent with previous studies (e.g. Brun et al., 2013) which found that the thermal state of the snow-covered ground was only moderately impacted by variations of its composition. Of course, studies specifically targeting the thermal state of the ground would require refining the assumption made here. In the case of table snowpacks, the model was modified so that air temperature was imposed on all soil layers below $10 \mathrm{~cm}$. This solution was found to adequately reproduce the thermal behaviour of the snowpack lying on tables without explicitly accounting for the bottom energy balance of the snowpack, which would be beyond the scope of these numerical simulations. In this case, the top $10 \mathrm{~cm}$ of soil acted in particular to dampen thermal fluctuations of air temperature and prevent extensive snow melt at the base when the temperature reached $0{ }^{\circ} \mathrm{C}$. The snowpack scheme Crocus represents the snowpack as a stack of a variable number of snow layers, depending on the total snow depth and the vertical profile of its physical properties. For this study, consistent with common practice for a seasonal snowpack (Vionnet et al., 2012), the maximum number of snow layers was 50 . The model uses an internal time step of 15 min to solve the surface energy and mass balance budget, the heat diffusion equation through the snow and the soil, and the time evolution of the physical properties of snow such as density, liquid water content and microstructure variables (see Vionnet et al., 2012 for full details on the model). The model output consists of time series of the vertical profile of the state physical variables of the snowpack and the underlying soil. In this work, emphasis is placed on the vertical profile of snow temperature, density, snow type and snow SSA. We used several model configurations to address the impact of various representations of snow metamorphism in detailed snowpack model on simulated SSA, density and permeability. In the base model configuration, snow microstructure, besides density, is characterized by the snow dendricity, sphericity and visible grain size (Brun et al., 1992; Vionnet et al., 2012). Snow metamorphism laws are used to compute the time evolution of these variables depending on the temperature, temperature gradient, and liquid water content of the snow layers. In this case, referred to as B92, the SSA of each layer is computed using empirical relationships using dendricity, sphericity and visible grain size (see Morin et al., 2013 for details). Recent work now makes it possible in Crocus to explicitly represent the time evolution of snow SSA in each layer using prognostic equations operating on this variable (Carmagnola et al., 2013). In this case, snow microstructure is represented in each layer by snow density, SSA and sphericity. Besides a reformulation of the original snow metamorphism in this new formalism (referred to as C13 option), this development also allows the use of alternative snow SSA evolution laws, in particular the Flanner and Zender (2006) parameterization (referred to here as F06). Because some of the snow SSA evolution laws were partly derived from the same experimental data set, we do not consider here the snow SSA evolution laws of Taillandier et al. (2007). Model runs using the B92, C13 and F06 configurations were carried out. For the sake of brevity, only the B92 results are shown in detail. In all cases, snow permeability was computed from model-derived snow SSA and snow density according to Eq. (3) (Calonne et al., 2012).

The only deviation from the standard version of Crocus pertains to the parameterization of snow viscosity. In physically based detailed snowpack models, snow viscosity is classically parameterized as a function of snow density and temperature (Essery et al., 2013), and generally increases with decreasing temperature. In Crocus, the temperature dependence of snow viscosity is the multiplicative factor $\exp \left(\alpha_{\eta}\left(T_{\text {fus }}-T\right)\right)$, where $T_{\text {fus }}$ is the ice melting temperature, $T$ is the temperature of the snow layer, and the empirical parameter $\alpha_{\eta}=0.1 \mathrm{~K}^{-1}$ (Vionnet et al., 2012), leading to extremely high viscosity values as soon as the snow temperature becomes lower than $-10^{\circ} \mathrm{C}$. In order to prevent the model from unrealistically computing low snow compaction under sustained extremely low temperature 


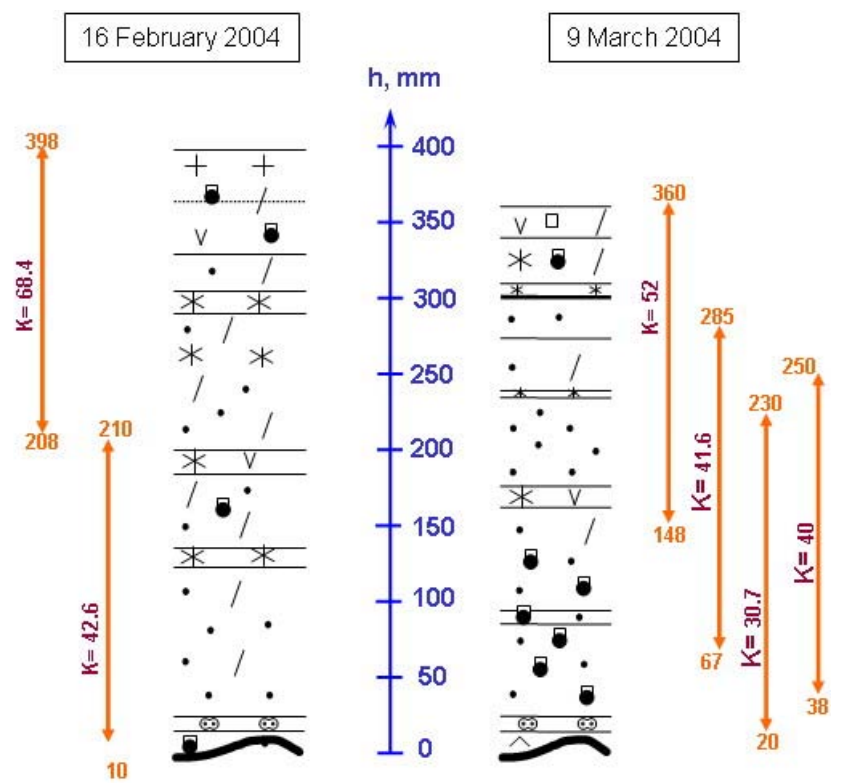

Fig. 2. Same as Fig. 1, for the table snowpack.

conditions prevailing in the table snowpack (see below), the maximum impact of snow temperature on snow viscosity was bounded to a factor 2 . We tested the fact that this modification has no detrimental effect on simulations carried out for snowon-the-ground situations in environmental contexts, such as alpine snowpacks and snow on the ground in northern Eurasia, using the driving and evaluation data sets described by Morin et al. (2012) and Brun et al. (2013), respectively.

To obtain a correct thermal state of the soil in our coupled soil-snow model, an eight-year spinup time was used and simulations were started on 1 July 1995 . Meteorological driving data for the model consist of air temperature and humidity, wind speed, liquid and solid precipitation rates, and shortwave and longwave downwards radiation. For this study, we used three-hourly data from the ERA-Interim (Dee et al., 2011) meteorological reanalysis. Brun et al. (2013) have shown that using simulations covering northern Eurasia driving Crocus with ERA-Interim leads to accurate simulations of the snow depth and snow water equivalent (SWE) in mid-latitude low-altitude clearings, with typical biases and root mean square deviation (RMSD) of 3.9 and $11.7 \mathrm{~cm}$ for snow height, and 20.1 and $49.1 \mathrm{~kg} \mathrm{~m}^{-2}$ for snow water equivalent, respectively. Out of an extraction grid with a spatial resolution of $0.5^{\circ}$, the nearest grid point of the ERA-Interim meteorological reanalysis to the LARS was chosen, with coordinates $65^{\circ} \mathrm{N}-148^{\circ} \mathrm{W}$ (i.e., about $12 \mathrm{~km}$ from the LARS station) and a surface altitude of $341 \mathrm{~m}$. The three other grid points of the ERA-Interim analysis around the LARS site were also inspected, with minimal differences in terms of meteorological forcing. Differences of meteorological fields arising from the $121 \mathrm{~m}$ altitude difference between the model grid point and the experimental site were corrected using the approach described by Cosgrove et al. (2003) and used by Brun et al. (2013). The correction of the altitude difference has an insignificant impact on the meteorological forcing data and the model output. Indeed, the temperature difference is $0.85 \mathrm{~K}$ and the corresponding change in precipitation phase leads to a variation from $83.3 \%$ snow precipitation at the altitude of the ERA-Interim point to $82.0 \%$ at the LARS altitude, while the total precipitation remains the same. In terms of snow simulations, for example, this change induces a mean variation of $1.6 \pm 2.2 \mathrm{~cm}$ for simulated snow height during the measurement period. The sheltered conditions of the site made the ERA-Interim wind speed data generally about twice as high as in situ data; to mitigate this discrepancy and carry out simulation using realistic meteorological driving data, ERA-Interim wind data were divided by two throughout the whole period for which such forcings are available. However, starting on 29 October 2003 and until 22 April 2004, in situ wind measurements were used instead of the ERA-Interim data.

\section{Results}

\subsection{Description of observed snow conditions and snow stratigraphic profiles on ground and tables}

\subsubsection{Snow on the ground}

Data obtained on the stratigraphy, temperature gradient, density and SSA of the ground snowpack have been detailed by Taillandier et al. (2006). Additional data on this type of snowpack, and in particular details of the metamorphism of snow crystals to depth hoar, are found in Sturm and Benson (1997). Briefly, the temperature gradient in the whole snowpack decreased from a peak of $198 \mathrm{~K} \mathrm{~m}^{-1}$ in November 2003 to a value oscillating around $20 \mathrm{~K} \mathrm{~m}^{-1}$ in March. Most of the precipitation took place in the fall so that in early December the snowpack was already $40 \mathrm{~cm}$ thick. In early January, half of the snowpack had transformed into depth hoar, the rest being mostly faceted crystals. In late March, most of the snowpack was depth hoar, with faceted crystals near the top. The density was around $200 \mathrm{~kg} \mathrm{~m}^{-3}$ throughout most of the snowpack, except near the top with values typically near $120 \mathrm{~kg} \mathrm{~m}^{-3}$. The SSA of the depth hoar was in the range 6 to $14 \mathrm{~m}^{2} \mathrm{~kg}^{-1}$, decreasing over time, while faceted crystals showed values between 9 and $17 \mathrm{~m}^{2} \mathrm{~kg}^{-1}$. Permeability profiles are shown in Fig. 1, along with the stratigraphic profiles. Given that cores are about $20 \mathrm{~cm}$ high, overlapping cores were sampled, so that what was actually measured was an average over the core.

\subsubsection{Snow on tables}

Results from snow on tables have not been described in as much detail as for snow on the ground. Taillandier et al. (2007) briefly discussed SSA data and metamorphic 


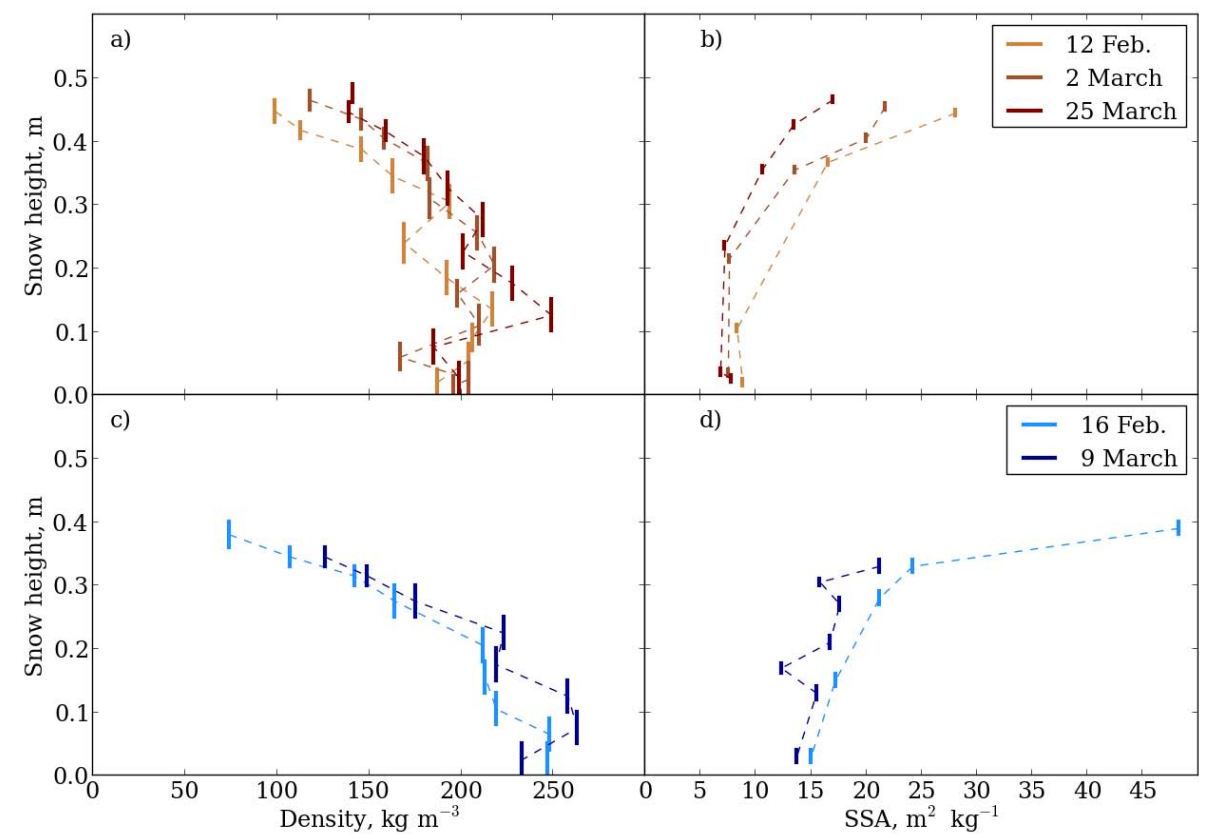

Fig. 3. Vertical profiles of density (left, a, c) and specific surface area (SSA) (right, b, d) for the ground (top, a, b) and table (bottom, c, d) snowpacks. The height of the vertical bars shows the range of snow heights that were actually sampled. The dotted lines join the middle height of samples belonging to the same vertical profile.

conditions. More information is given here. Stratigraphic profiles and permeability values for the table snowpack are shown in Fig. 2. The stratigraphic profiles consist mostly of rounded or little-transformed crystals, which confirms that the table snowpack evolved essentially under ET conditions, even though thermal cycling in March did induce transient thermal gradients that produced some slight faceting. Density and SSA profiles are shown in Fig. 3, which also shows ground snowpack profiles for comparison. Snow crystal transformations were slow on the tables. Dendritic crystals had barely transformed and were still easily recognizable after several months in some thin very soft layers that were probably of very low density, but this variable could not be measured because of insufficient layer thickness. This is in agreement with the modeling study of Legagneux and Domine (2005), who showed that SSA decrease was much slower in low- than high-density snow under ET conditions. Figure 3 shows that the density profile on tables showed a decreasing trend in the top $20-30 \mathrm{~cm}$ of the snowpack, as expected from compaction under ET conditions. SSA essentially decreased towards the bottom, but values never went below $12 \mathrm{~m}^{2} \mathrm{~kg}^{-1}$, while they went below $7 \mathrm{~m}^{2} \mathrm{~kg}^{-1}$ on the ground, because higher temperature gradients accelerate SSA decrease.

\subsection{Observed time evolution of snow permeability}

Temporal variations of permeability are shown in Fig. 4 for various levels in the snowpacks. Since cores were about
$20 \mathrm{~cm}$ long, the levels indicate the middle of the core. Because core levels were not always exactly the same for all the days of the measurements, the actual level varies within a few $\mathrm{cm}$. Therefore, the measurements were divided into three classes representing the relative position of snow samples within the snowpack stratigraphy (top, middle and bottom). This allows the representation of the time evolution of snow permeability of approximately the same snow layers, taking into account snow compaction. Obvious trends in Fig. 4 are that $K$ increases with time on the ground and in contrast decreases with time on the tables.

\subsection{Relationship between measured $K, \rho$ and SSA}

The present data, which combine collocated SSA, density and permeability measurements, can be used to test the relationship between these variables presented by Calonne et al. (2012). Figure 5 shows our data plotted together with Eq. (3) and the previous data of (Calonne et al., 2012). Other relevant data by Arakawa et al. (2009), Sommerfeld and Rocchio (1993), Courville et al. (2010) are not reported here for clarity but can be seen in a similar graph in Calonne et al. (2012). Table 1 summarizes all the collocated measurements of permeability, SSA and density data reported in this study. The agreement is reasonable, considering that our permeability measurements involve a $20 \mathrm{~cm}$ core, while SSA and density measurements have a resolution of $5 \mathrm{~cm}$ or better. This inevitably produces error and data scatter because the average permeability $K$ of a core of height $H$ formed of $n$ layers 


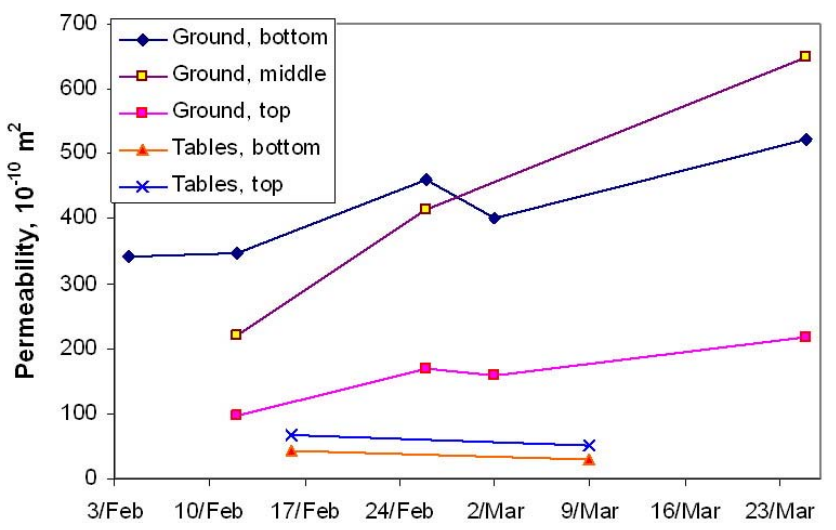

Fig. 4. Time evolution of snow permeability on the table and ground, for different regions of the snowpack. Heights where measurements were made are not exactly constant, due to variations in the location of the cores and to compaction of the layers that were followed. Average heights of the center of the cores used were (above ground) 11, 26 and $39 \mathrm{~cm}$ for the bottom, middle and top cores on the ground, and 12 and $27 \mathrm{~cm}$ for the bottom and top cores on the tables, respectively. Isolated data points obtained on 4 and 26 February, not shown in Fig. 1, have been reported here.

of heights $H_{i}$ and permeabilities $K_{i}$ is given by

$\frac{H}{K}=\sum_{1}^{n} \frac{H_{i}}{K_{i}}$,

so that equal thickness low-permeability layers have more influence on the overall core permeability than highpermeability layers.

\subsection{Modeling results: overview of the simulations}

Prior to an in-depth analysis of the numerical simulations in terms of the vertical profile of the physical properties of snow, the simulations are evaluated against measured total snow height values. Figure $6 \mathrm{a}$ and $\mathrm{b}$ shows the observed and simulated total snow height on tables and on ground, respectively. The simulations on tables show reasonable agreement between observations and simulations (bias and root mean square deviation (RMSD) of 3.8 and $8.4 \mathrm{~cm}$, respectively). The model results overestimate total snow height, especially starting in mid-January, when wind erosion was observed to happen on tables (but not on the ground) at the site during the experiment, which may explain the observed discrepancy. On the ground, the results of the simulations are in excellent agreement with the observations (bias and RMSD of -1.0 and $4.0 \mathrm{~cm}$, respectively). Similar statistical scores were obtained using the alternative snow metamorphism formulations (Carmagnola et al., 2013; Flanner and Zender, 2006). Figure $6 \mathrm{~b}$ also displays the total snow height simulated by Jacobi et al. (2010) using the stand-alone version of Crocus including the standard snow viscosity parameterization with temperature. The bias and RMSD of that simulation were

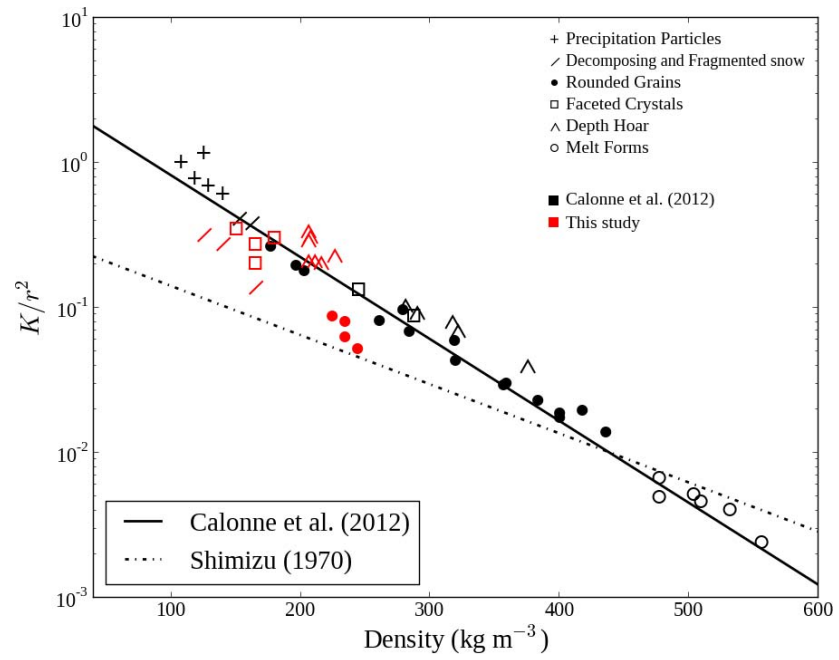

Fig. 5. Comparison of our experimental data (in red) with Eq. (3). Data from Calonne et al. (2012) are also shown. The widely used equation of Shimizu (1970) is also plotted. In that case, note that $r$ corresponds to the visual grain radius $r_{\text {vis }}$.

-1.8 and $3.9 \mathrm{~cm}$, respectively, consistent with our simulations. Note, however, that to achieve such good results in terms of total snow height, Jacobi et al. (2010) needed to manually adjust the ground flux of the stand-alone Crocus simulation. In contrast, our simulations take full advantage of the explicit coupling between the snowpack and the underlying ground, resulting in excellent agreement between model and observations without any tuning of the ground flux (Brun et al., 2013). This is best exemplified by the comparison between observed and simulated soil surface temperature (Fig. 6c).

\subsection{Modeling results: seasonal overview of the time evolution of physical properties of the snowpack}

Figures 7 and 8 show the simulated time evolution of the vertical profiles of several key physical snow variables: temperature, absolute value (or modulus) of the temperature gradient and main snow type, and snow density, snow SSA and snow permeability on ground and tables. The model illustrates well the contrasted thermal field within the snow between the ground and tables cases. On ground, strong vertical gradients developed throughout the season, while on tables the model predicts limited temperature gradients and comparably much colder conditions (Fig. 7a-d). Since the time evolution of the snow type depends strongly on temperature and temperature gradient in Crocus (Brun et al., 1992; Vionnet et al., 2012), these results expectedly translate into widely different predicted snow types, as shown in Fig. 7e, f. Snow on tables is simulated to evolve slowly into rounded grains and faceted crystals, while snow on the ground evolves much quicker into mostly depth hoar. Snow type simulations are mostly consistent with observations. However, the transformation of 
Table 1. Overview of combined snow permeability, density and SSA data acquired in the field during the experiment.

\begin{tabular}{llrrrrrl}
\hline Date & Location & $\begin{array}{r}\text { Height } \\
\text { min }\end{array}$ & Density & SSA & Permeability & Snow type \\
& & $\mathrm{cm}$ & $\mathrm{cm}$ & $\mathrm{kg} \mathrm{m}^{-3}$ & $\mathrm{~m}^{2} \mathrm{~kg}^{-1}$ & $10^{-10} \mathrm{~m}^{2}$ & ICSSG \\
\hline 12 Feb 2004 & Ground & 37 & 47 & 120 & 18 & 97 & DF(FC) \\
12 Feb 2004 & Ground & 19 & 36 & 175 & 11 & 222 & FC \\
12 Feb 2004 & Ground & 6 & 23 & 201 & 8 & 476 & DH \\
12 Feb 2004 & Ground & 4 & 20 & 210 & 7 & 346 & DH \\
12 Feb 2004 & Ground & 0 & 17 & 205 & 7 & 374 & DH \\
16 Feb 2004 & Table & 21 & 40 & 135 & 20 & 68 & DF(RG) \\
16 Feb 2004 & Table & 1 & 21 & 220 & 14 & 43 & RG(DF) \\
2 Mar 2004 & Ground & 26 & 48 & 145 & 15 & 159 & FC(DH) \\
2 Mar 2004 & Ground & 22 & 44 & 160 & 12 & 128 & FC(DH) \\
2 Mar 2004 & Ground & 9 & 31 & 200 & 8 & 398 & DH \\
2 Mar 2004 & Ground & 0 & 22 & 200 & 7 & 400 & DH \\
9 Mar 2004 & Table & 15 & 36 & 160 & 16 & 52 & DF(RG) \\
9 Mar 2004 & Table & 7 & 29 & 230 & 14 & 42 & RG(FC) \\
9 Mar 2004 & Table & 4 & 25 & 230 & 12 & 40 & RG(FC) \\
9 Mar 2004 & Table & 2 & 23 & 240 & 13 & 31 & RG(FC) \\
25 Mar 2004 & Ground & 27 & 48 & 160 & 11 & 219 & FC(DH) \\
25 Mar 2004 & Ground & 16 & 36 & 200 & 7 & 648 & DH(FC) \\
25 Mar 2004 & Ground & 0 & 22 & 220 & 6 & 522 & DH \\
\hline
\end{tabular}

basal melt forms into depth hoar on the ground, visible in Fig. 1 and detailed in Domine et al. (2009), is not simulated here. Likewise, the preservation of dendritic crystals within the snowpack until the end of the season (Fig. 2) is not reproduced, but the layers involved are very thin, so that the layer treatment in Crocus does not allow the conservation of these limited amounts of precipitation as individual layers (Vionnet et al., 2012). Simulations on tables show the evolution of snow layers into faceted crystals, which was not observed in the field to such a large extent; however, it is important to keep in mind that the conversion of continuous physical properties of snow into discrete snow types leads to threshold effects, which may explain the apparent inconsistency.

The time evolution of the physical properties of all the snow layers making up the snowpack (density, SSA and permeability) is displayed in Fig. 9. These three variables were binned using snow layer age since snowfall with a bin size of one day, and the average and standard deviation, were computed within each bin. The density increases in both cases at a comparable rate, and SSA exhibits a faster decrease on the ground (larger temperature and temperature gradient) than on tables, consistent with the present field experiment and previous investigations (Taillandier et al., 2007; Flanner and Zender, 2006). The time evolution of snow permeability shows contrasted time evolutions. On tables, $K$ initially increases from values on the order of 30 to $60 \times 10^{-10} \mathrm{~m}^{2}$ in fresh snow to reach a maximum value around $200 \times 10^{-10} \mathrm{~m}^{2}$ after ca. 20 days, and then starts to decrease. On ground, values keep increasing up to about $1000 \times 10^{-10} \mathrm{~m}^{2}$ after 60 to 70 days, where permeability values tend to stabilize or perhaps

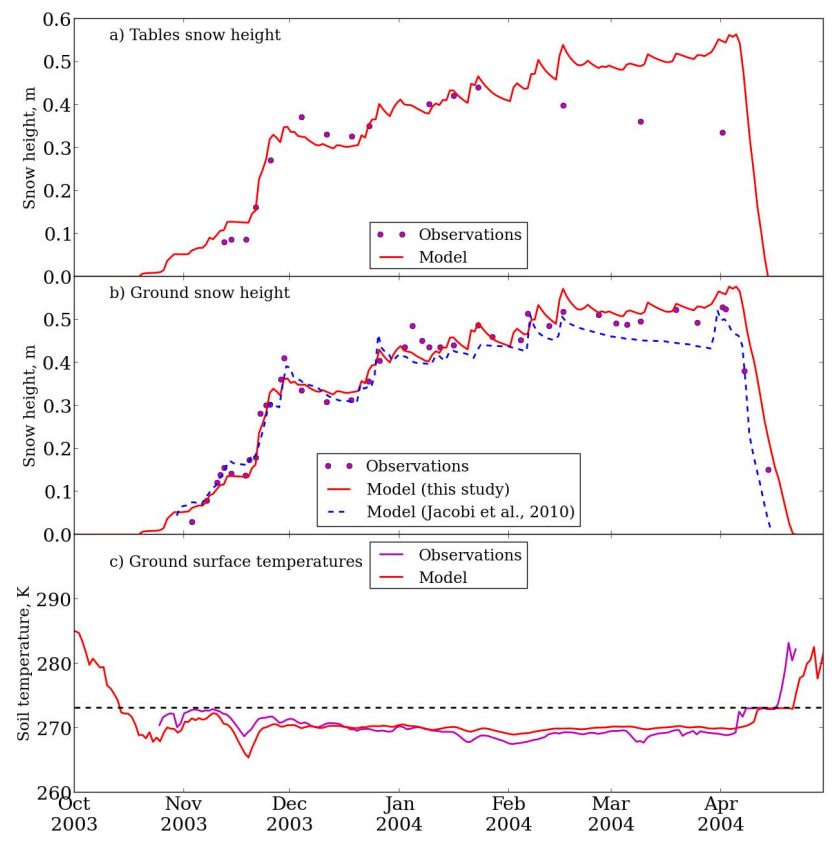

Fig. 6. Simulations of the seasonal evolution of snowpack height with Crocus. (a) On tables; (b) on the ground. Experimental data and the previous work of Jacobi et al. (2010) are also shown for comparison. Panel (c) displays the simulated and observed ground surface temperature. 


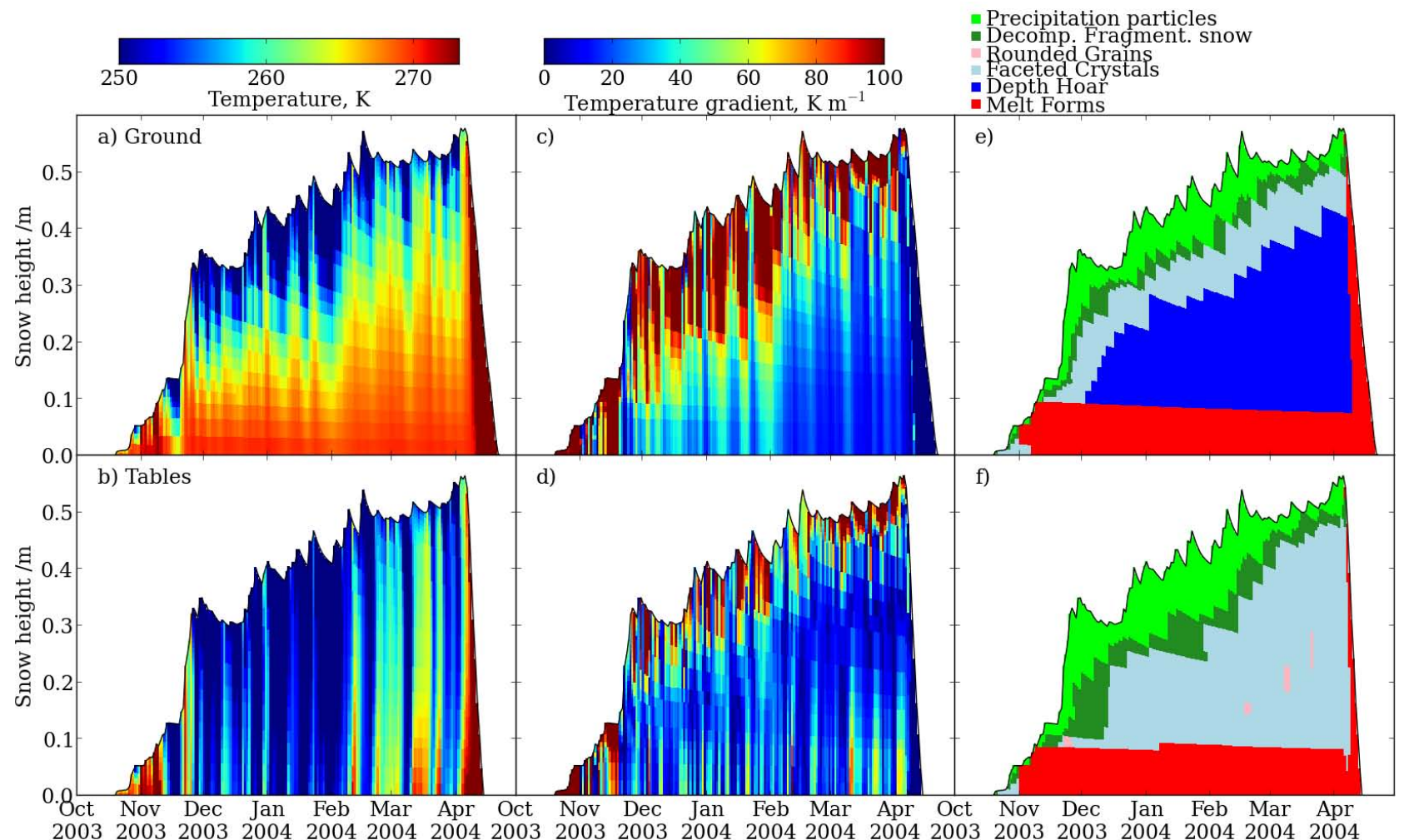

Fig. 7. Simulations of the vertical profiles of temperature $(\mathbf{a}, \mathbf{b})$, absolute value (or modulus) of the temperature gradient (c, $\mathbf{d})$ and snow type $(\mathbf{e}, \mathbf{f})$ on the ground $(\mathbf{a}, \mathbf{c}, \mathbf{e})$ and on tables $(\mathbf{b}, \mathbf{d}, \mathbf{f})$ simulated using the snowpack model Crocus, over the whole season.

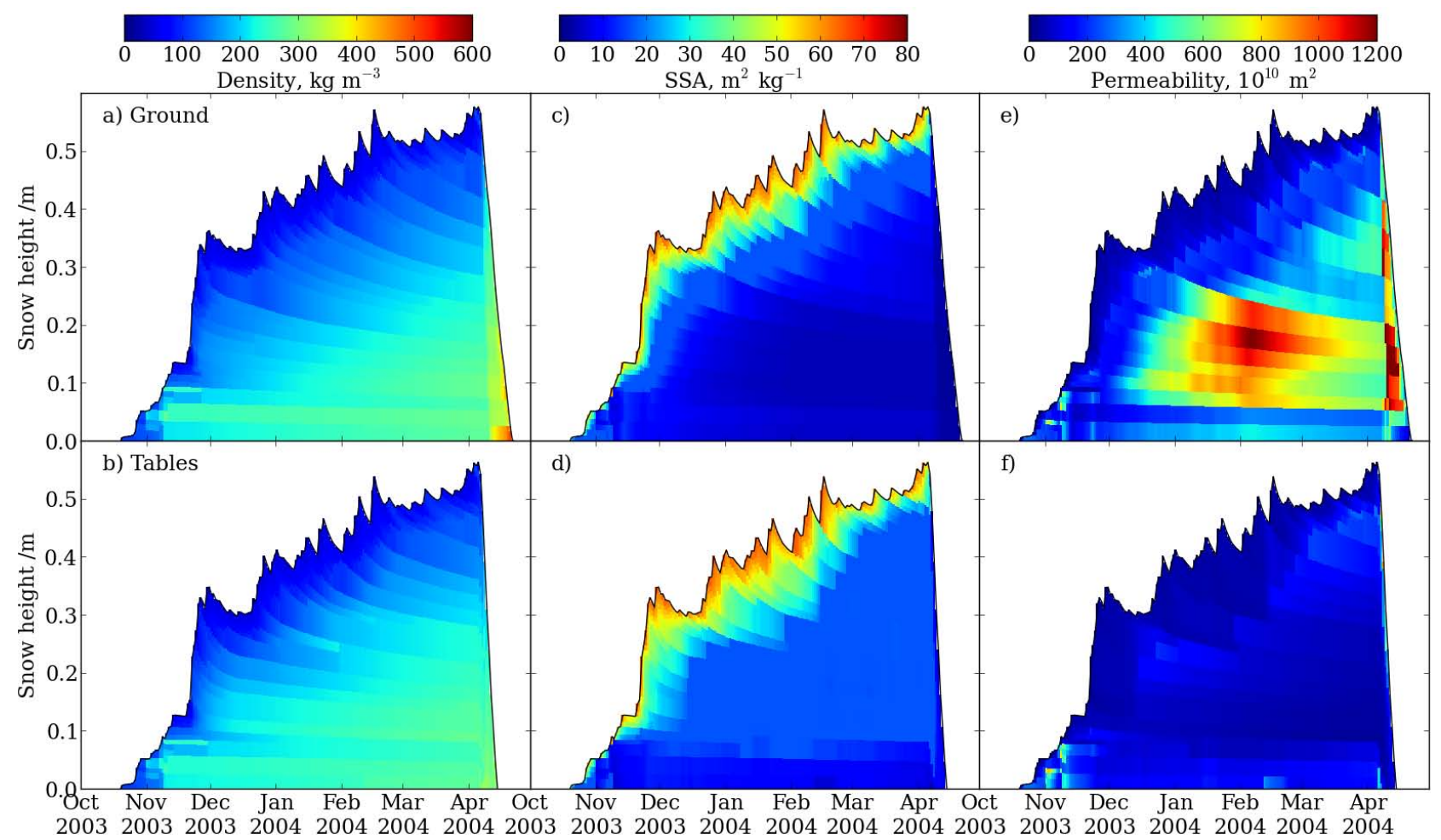

Fig. 8. Simulations of the vertical profiles of density (a, b), SSA (c, d) and permeability (e, f) on the ground (a, c, e) and on tables $(\mathbf{b}, \mathbf{d}, \mathbf{f})$ simulated using the snowpack model Crocus, over the whole season. 
show an insignificant decrease. Here again, the model results follow qualitatively the experimental data reported in Fig. 4.

\subsection{Comparison of simulated and observed vertical profiles}

Quantitative comparisons between observations and simulations of snow density, SSA and permeability were carried out, and we present here the data for those profiles for which all 3 variables were measured. Figures 10 and 11 show the measured and simulated profiles of the three variables on ground ( 3 profiles) and on tables ( 2 profiles). They illustrate in greater detail than previously the agreement and discrepancy between observed and simulated physical properties of snow. To quantitatively compare observed and simulated data, the high-resolution simulated profiles were integrated over the measurement height. In the case of SSA and density, the weighting was carried out as a function of the layer thickness. In the case of permeability, Eq. (5) was used. Table 2 summarizes the model/measurements RMSD and bias for these three variables. While all the graphical results presented above apply to the standard snow metamorphism laws originally implemented in Crocus (Brun et al., 1992; Vionnet et al., 2012), referred to as B92, results for alternative simulations carried out using prognostic equations for SSA evolution (Carmagnola et al., 2013), either reformulating existing laws (C13) or using the Flanner and Zender (2006) parameterizations, are also provided in Table 2 .

On the ground, the main discrepancies are the strong overestimation of snow density in the lowermost part of the snowpack, up to $100 \mathrm{~kg} \mathrm{~m}^{-3}$. This discrepancy decreases towards the end of the season. On tables, the main discrepancies lie in the upper part of the profile, due to the overestimation of total snow height by the model. The main cause of this overestimation is wind erosion, which was observed at the site but not accounted for in the model simulations. In terms of snow SSA, the agreement between the model and the observations is very satisfying, with negligible bias on tables and on the ground. The striking difference between the observed and simulated profiles of snow permeability is the existence of several layers with a high permeability in the middle of the ground snowpack, featuring permeability values above $1000 \times 10^{-10} \mathrm{~m}^{2}$. None of the measurements display such high values, which is only in part due to the averaging procedure: vertically integrated values are generally higher than the corresponding observed data, with up to a factor 2 difference. The average bias between model results and measurement is on the order of $40 \%$ with a RMSD of $40 \%$, which is encouraging given the large scatter in existing field measurements of permeability (Calonne et al., 2012) and the many possible sources of error of the simulated data, which include errors in the meteorological driving data, errors of the representation of physical processes in the model (simplifications, uncertain model parameters, ...) and uncertain physical variables describing the environmental setting (such as

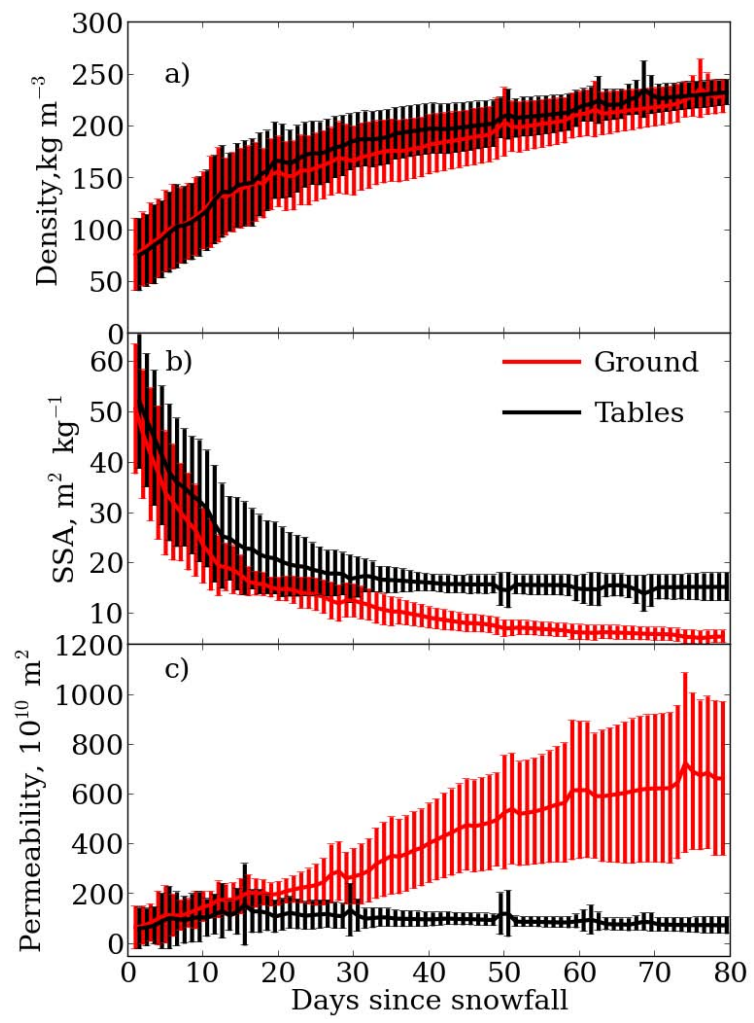

Fig. 9. Time evolution of the simulated physical properties of all the snow layers making up the snowpack (density, SSA and permeability). These three variables were binned using snow layer age since snowfall with a bin size of one day, and the average and standard deviation were computed within each bin. The standard deviation is displayed using the error bar symbols. The different evolution on tables and ground shows clearly.

ground properties). The results of the three snow metamorphism schemes used in this study to represent the time evolution of SSA, summarized in Table 2, do not show significant differences, consistent with the results of Carmagnola et al. (2013) obtained in terms of snow SSA and density in a range of conditions spanning maritime (Col de Porte, France) and polar conditions on the Greenland ice sheet. This shows that errors in the representation of the time evolution of snow SSA do not seem to be the main driver of uncertainty for the numerical simulation of the time evolution of snow permeability.

\section{Discussion}

\subsection{Comparison between measurements and model}

Despite the generally good agreement between measurement and model seen in Figs. 6, 10 and 11, some differences require discussion. The first one is the density profiles of the ground snowpack. While measurements show fairly flat profiles with densities in the lower two-thirds essentially 
Table 2. Statistical summary of relative differences between simulated and observed properties of the snowpack (density, SSA and permeability). $n$ refers to the number of data used to compute the statistics. Statistics are given not only for the base run using the standard metamorphism law in Crocus (B92), but also using two alternative formulations with prognostic SSA time evolution described in Carmagnola et al. (2013; C13) and Flanner and Zender (2006; F06).

\begin{tabular}{llrr|rr|rr|rr}
\hline & & & \multicolumn{2}{c}{ B92 } & \multicolumn{2}{c}{ C13 } & \multicolumn{3}{c}{ F06 } \\
\cline { 3 - 9 } & & & bias & RMSD & bias & RMSD & bias & RMSD \\
\hline Density $\left(\mathrm{kg} \mathrm{m}^{-3}\right)$ & Ground & 34 & 15.7 & 39.9 & 16.8 & 38.3 & 11.9 & 35.9 \\
& Table & 17 & 23.7 & 30.3 & 25.9 & 32.8 & 23.6 & 30.7 \\
& All & 51 & 18.4 & 37.0 & 19.8 & 36.6 & 15.8 & 34.2 \\
\hline \multirow{3}{*}{ SSA $\left(\mathrm{m}^{2} \mathrm{~kg}^{-1}\right)$} & & & & & & & & \\
& Ground & 15 & -1.4 & 3.3 & -2.6 & 4.2 & -5.0 & 5.4 \\
& Table & 12 & -3.7 & 7.1 & -4.4 & 7.3 & -7.5 & 10.5 \\
& All & 27 & -2.4 & 5.3 & -3.4 & 5.8 & -6.1 & 8.1 \\
\hline \multirow{2}{*}{ Permeability $\left(10^{-10} \mathrm{~m}^{2}\right)$} & Ground & 11 & 156.5 & 261.4 & 328.2 & 444.8 & 291.8 & 326.4 \\
& Table & 6 & 18.5 & 19.0 & 22.6 & 23.4 & 66.8 & 67.7 \\
& All & 17 & 107.8 & 210.6 & 220.3 & 358.1 & 212.4 & 265.6 \\
\hline
\end{tabular}

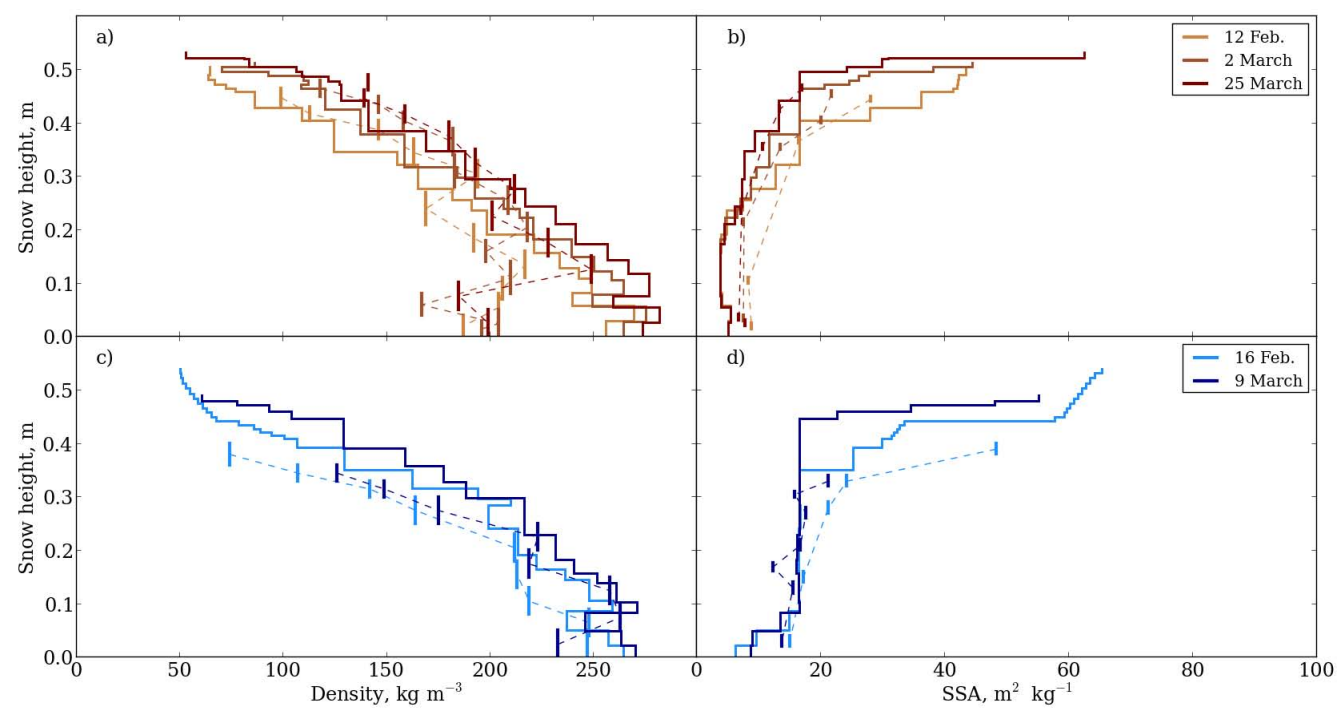

Fig. 10. Comparison of simulated and measured snow density (left, a, c) and SSA (right, b, d) for the ground (top, a, b) and table (bottom, c, d) snowpacks. Data are shown for the five profiles measured. Continuous lines are for simulations.

constant around $200 \mathrm{~kg} \mathrm{~m}^{-3}$, simulations show a profile that decreases with height. We believe that this is because Crocus does not currently take into account the upward water vapor flux induced by the large temperature gradient. Sturm and Benson (1997) showed with water isotopes measurements that these fluxes indeed led to extensive mass redistribution.

The largest difference is between measured and simulated permeabilities, and the difference reaches a factor of two for some of the depth hoar samples. We propose that this may be explained by the peculiar shapes of depth hoar crystals. Permeability estimates are based on density and SSA according to Eqs. (3) and (4). Taillandier et al. (2007; their
Fig. 1) showed that depth hoar crystals, which are hollow, have a much larger visible size than predicted by Eq. (4). Following Taillandier et al. (2007), a depth hoar crystal with $\mathrm{SSA}=16.4 \mathrm{~m}^{2} \mathrm{~kg}^{-1}$ has an equivalent sphere diameter of $0.4 \mathrm{~mm}$, but its visually determined radius is $>2 \mathrm{~mm}$. Its aerodynamic drag will therefore be much larger than that of the small sphere, leading to a lower permeability than predicted by spheres of the same SSA. The fact that larger grains will lead to lower permeability seems contradictory to Eq. (3). However, that equation is particularly suited to predict the effect of an increase in equivalent sphere size in the case of near-spherical grain geometry. Shape is another 

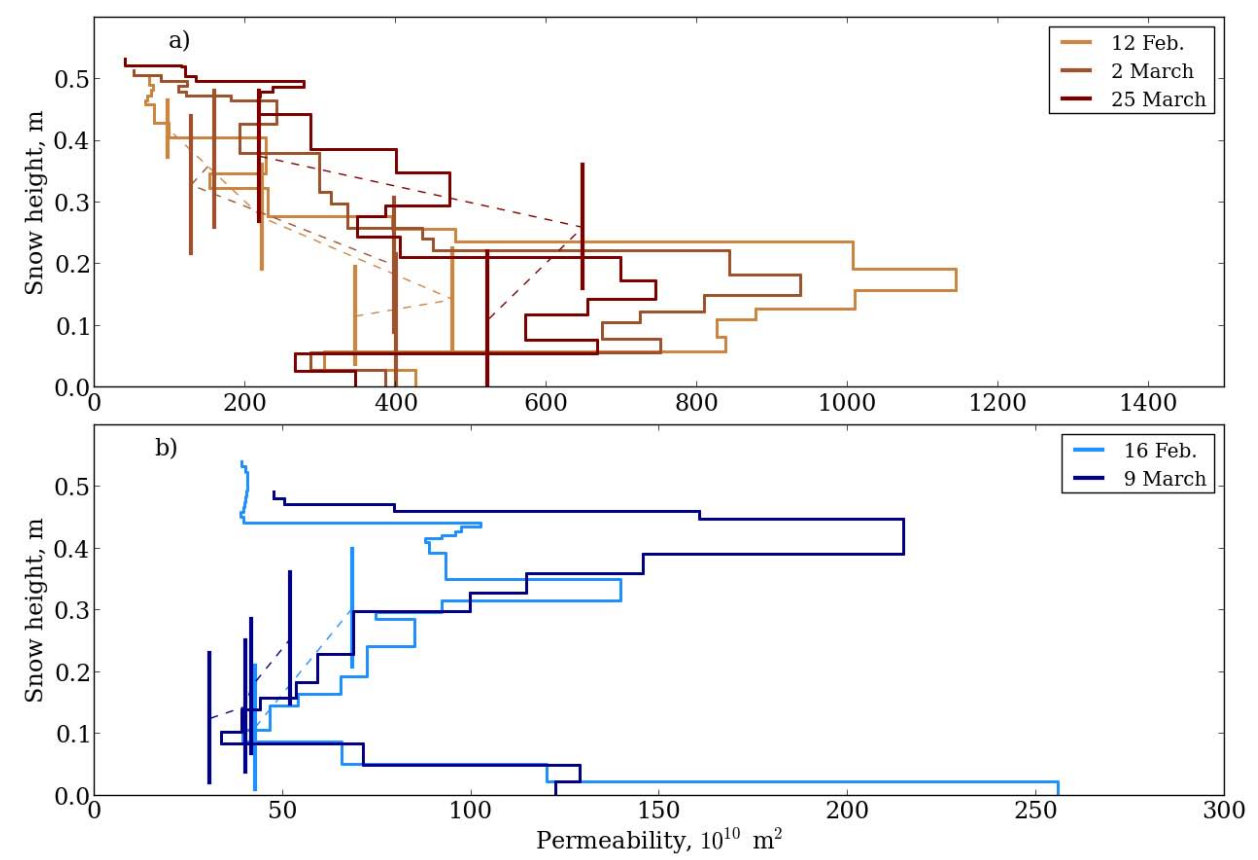

Fig. 11. Same as Fig. 10 for the permeability.

important factor that affects permeability (Dullien, 1992). Replacing spheres of a given SSA with large hollow crystals of the same SSA would decrease pore diameter and therefore restrict flow. Furthermore, our measurement method had air flowing from bottom to top. Since depth hoar crystals are shaped as hollow cups with their opening facing down (Sturm and Benson, 1997), this configuration will maximize drag, also reducing air flow and decreasing permeability. In summary, we suggest that the differences between measurement and model are caused by microstructure factors beyond SSA and density, which the permeability parameterization does not account for. This stresses the need for further studies addressing the complex relationships between permeability and microstructure (not only density and SSA) in parallel to model developments aimed at simulating the relevant microstructure variables needed for such improved parameterizations.

\subsection{Metamorphism, climate and permeability}

This study constitutes a novel illustration of the difference between ET and TG metamorphism, already well documented with regards to crystal morphology and density (e.g. Colbeck, 1983; Sommerfeld and LaChapelle, 1970) and to SSA (Taillandier et al., 2007). Here we show that these different regimes manifest themselves very clearly in permeability values and in the time evolution of permeability. In the ET regime, compaction reduces porosity, contributing to permeability decrease over time. Figure 4 shows that this decrease is not compensated by the decrease in SSA, which should lead to a permeability increase, as indicated by Eq. (3). In the intense TG conditions of the ground snowpack, the formation of large grains and the lack of compaction beyond densities of about $200 \mathrm{~kg} \mathrm{~m}^{-3}$, coupled to a rapid SSA decrease, results in the formation of large pores that facilitate air flow, so that values exceed $500 \times 10^{-10} \mathrm{~m}^{2}$ in the bottom half of the snowpack at the end of the season. We note however that we measured vertical permeability, while air advection will also be sensitive to horizontal permeability. Calonne et al. (2012) have calculated that anisotropy might reach a factor of 1.6 for depth hoar, so that horizontal permeability could be somewhat lower than what we measured. Further delicate measurements are required to confirm these calculations. Still, at the end of the season, permeability in TG snow is much greater than in ET snow, by a factor of 10 for vertical permeability.

This indicates that changes in snow properties due to climate change (Domine et al., 2007a) will affect both energy transfer due to air advection and convection and the deposition of chemicals to snow by the filtering of advected air. These effects should be taken into account when quantifying snow-climate feedbacks. Detailing them is beyond our scope but a couple of examples may be mentioned. First the warming of the boreal forest will limit depth hoar development and therefore reduce both above effects. Second, changes in the properties of tundra snowpacks (Domine et al., 2012) are more complex. The warming-induced growth of vegetation will change snow properties by sheltering snow from wind effects and limiting the formation of low-permeability Arctic wind slabs usually with a marked surface roughness due to their mode of formation (Gouttevin et al., 2012). The 
development of depth hoar, with a greater permeability but with a lower surface roughness, will be more likely. The overall effect of these changes from wind slab to depth hoar on air advection in snow is difficult to predict. Increased permeability will favor advection, while decreased surface roughness will reduce it. Since wind pumping (Colbeck, 1989; Cunningham and Waddington, 1993) on rough surface can show effects down to depth of $1 \mathrm{~m}$ (Albert and Schultz, 2002), this effect may be worth further consideration. The impact of rain-on-snow events should also be included in such a discussion, but given the prevailing dry snow conditions encountered here, this is better considered to be beyond the scope of our study. Determining the resulting effect on energy and chemical transfer in the top layers of the snowpacks will require further work that takes into account changes in wind speed, snow permeability and surface roughness.

\section{Conclusions}

Regarding the main four objectives of this study, we conclude that the metamorphic regime of the snow has a very strong effect on snow permeability and on its evolution. The TG regime leads to high values increasing over time, while the ET regime features low values decreasing over time. As shown in Fig. 5, Eq. (3) is verified by our measurements, despite the fact that we used vertical cores about $20 \mathrm{~cm}$ high, where low permeability layers have an important effect. This equation, when applied together with outputs of the snowpack model Crocus using various formulations of snow SSA evolution, allows the reasonable simulation of snow permeability. However, differences of up to a factor of two were observed for depth hoar layers on the ground snowpack, suggesting that a better representation of snow microstructure (e.g. grain shape) should be taken into account for improved accuracy in simulating snow permeability.

Acknowledgements. The experimental part of this work was partially supported by Chapman Chair funds, kindly supplied by the late Norbert Untersteiner during F. Domine's stay at the Geophysical Institute, University of Alaska Fairbanks. F. Domine is very indebted to W. R. Simpson for organizing his stay at UAF, and thanks M. Sturm for the use of the permeameter, as well as A.-S. Taillandier for assistance with some of the measurements. B. Hauer very kindly proposed the LARS site for the experimental part of this study and provided assistance throughout the field work. We are grateful to numerous CNRM-GAME colleagues, in particular J.-M. Willemet, the SURFEX support team for their help in maintaining and using the model, F. Flin and N. Calonne for discussions related to snow permeability estimates from snow microstructure variables, and S. Tyteca for support regarding the ERA-Interim data set. We thank C. Fierz (WSL-SLF Davos) and two anonymous reviewers for useful comments and suggestions during the Discussion phase.

Edited by: M. Schneebeli

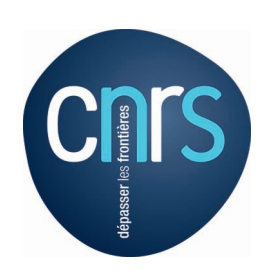

The publication of this article

is financed by CNRS-INSU.

\section{References}

Albert, M. R. and Hardy, J. P.: Ventilation experiments in a seasonal snow cover, in: Biogeochemistry of Seasonally SnowCovered Catchments, IAHS Publications, Boulder, CO, 1995, 41-49, 1995.

Albert, M. R. and Perron, F. E.: Ice layer and surface crust permeability in a seasonal snow pack, Hydrol. Process., 14, 3207-3214, 2000.

Albert, M. R., Shultz, E. F., and Perron, F. E.: Snow and firn permeability at Siple Dome, Antarctica, Ann. Glaciol., 31, 353-356, 2000.

Albert, M. R. and Shultz, E. F.: Snow and firn properties and airsnow transport processes at Summit, Greenland, Atmos. Environ., 36, 2789-2797, 2002.

Arakawa, H., Izumi, K., Kawashima, K., and Kawamura, T.: Study on quantitative classification of seasonal snow using specific surface area and intrinsic permeability, Cold Reg. Sci. Technol., 59, 163-168, 2009.

Bartlett, S. J. and Lehning, M.: A theoretical assessment of heat transfer by ventilation in homogeneous snowpacks, Water Resour. Res., 47, W04503, doi:10.1029/2010WR010008, 2011.

Bottenheim, J. W., Netcheva, S., Morin, S., and Nghiem, S. V.: Ozone in the boundary layer air over the Arctic Ocean: measurements during the TARA transpolar drift 2006-2008, Atmos. Chem. Phys., 9, 4545-4557, doi:10.5194/acp-9-4545-2009, 2009.

Brun, E., David, P., Sudul, M., and Brunot, G.: A numerical-model to simulate snow-cover stratigraphy for operational avalanche forecasting, J. Glaciol., 38, 13-22, 1992.

Brun, E., Vionnet, V., Boone, A., Decharme, B., Peings, Y., Valette, R., Karbou, F., and Morin, S.: Simulation of northern Eurasian local snow depth, mass and density using a detailed snowpack model and meteorological reanalysis, J. Hydrometeorol., 14, 203-214, doi:10.1175/jhm-d-12-012.1, 2013.

Calonne, N., Geindreau, C., Flin, F., Morin, S., Lesaffre, B., Rolland du Roscoat, S., and Charrier, P.: 3-D image-based numerical computations of snow permeability: links to specific surface area, density, and microstructural anisotropy, The Cryosphere, 6 , 939-951, doi:10.5194/tc-6-939-2012, 2012.

Carmagnola, C. M., Morin, S., Lafaysse, M., Domine, F., Lesaffre, B., Lejeune, Y., Picard, G., and Arnaud, L.: Implementation and evaluation of prognostic representations of the optical diameter of snow in the detailed snowpack model SURFEX/ISBA-Crocus, The Cryosphere Discuss., 7, 4443-4500, doi:10.5194/tcd-74443-2013, 2013.

Clifton, A., Manes, C., Ruedi, J. D., Guala, M., and Lehning, M.: On shear-driven ventilation of snow, Bound.-Lay. Meteorol., 126, 249-261, doi:10.1007/s10546-007-9235-0, 2008.

Colbeck, S. C.: Theory of metamorphism of dry snow, J. Geophys. Res., 88, 5475-5482, 1983. 
Colbeck, S. C.: Air movement in snow due to windpumping, J. Glaciol., 35, 209-213, 1989.

Conway, H. and Abrahamson, J.: Air permeability as a textural indicator of snow, J. Glaciol., 30, 328-333, 1984.

Cosgrove, B. A., Lohmann, D., Mitchell, K. E., Houser, P. R., Wood, E. F., Schaake, J. C., Robock, A., Sheffield, J., Duan, Q. Y., Luo, L. F., Higgins, R. W., Pinker, R. T., and Tarpley, J. D.: Land surface model spin-up behavior in the North American Land Data Assimilation System (NLDAS), J. Geophys. Res., 108, D8845, doi:10.1029/2002jd003316, 2003.

Courville, Z., Hoerhold, M., Hopkins, M., and Albert, M.: LatticeBoltzmann modeling of the air permeability of polar firn, J. Geophys. Res., 115, F04032 doi:10.1029/2009jf001549, 2010.

Cunningham, J. and Waddington, E. D.: Air-flow and dry deposition of non-sea salt sulfate in polar firn - Paleoclimatic implications, Atmos. Environ. A-Gen., 27, 2943-2956, doi:10.1016/09601686(93)90327-u, 1993.

Decharme, B., Boone, A., Delire, C., and Noilhan, J.: Local evaluation of the Interaction between Soil Biosphere Atmosphere soil multilayer diffusion scheme using four pedotransfer functions, J. Geophys. Res., 116, D20126, doi:10.1029/2011jd016002, 2011.

Dee, D. P., Uppala, S. M., Simmons, A. J., Berrisford, P., Poli, P., Kobayashi, S., Andrae, U., Balmaseda, M. A., Balsamo, G., Bauer, P., Bechtold, P., Beljaars, A. C. M., van de Berg, L., Bidlot, J., Bormann, N., Delsol, C., Dragani, R., Fuentes, M., Geer, A. J., Haimberger, L., Healy, S. B., Hersbach, H., Holm, E. V., Isaksen, L., Kallberg, P., Kohler, M., Matricardi, M., McNally, A. P., Monge-Sanz, B. M., Morcrette, J. J., Park, B. K., Peubey, C., de Rosnay, P., Tavolato, C., Thepaut, J. N., and Vitart, F.: The ERA-Interim reanalysis: configuration and performance of the data assimilation system, Q. J. Roy. Meteor. Soc., 137, 553-597, doi:10.1002/qj.828, 2011.

Domine, F., Sparapani, R., Ianniello, A., and Beine, H. J.: The origin of sea salt in snow on Arctic sea ice and in coastal regions, Atmos. Chem. Phys., 4, 2259-2271, doi:10.5194/acp-4-2259-2004, 2004.

Domine, F., Taillandier, A. S., Houdier, S., Parrenin, F., Simpson, W. R., and Douglas, T. A.: Interactions between snow metamorphism and climate: physical and chemical aspects, in: Physics and Chemistry of Ice, edited by: Kuhs, W. F., Royal Society of Chemistry, UK, Cambridge, 27-46, 2007a.

Domine, F., Taillandier, A. S., and Simpson, W. R.: A parameterization of the specific surface area of seasonal snow for field use and for models of snowpack evolution, J. Geophys. Res., 112, F02031, doi:10.1029/2006jf000512, 2007b.

Domine, F., Albert, M., Huthwelker, T., Jacobi, H.-W., Kokhanovsky, A. A., Lehning, M., Picard, G., and Simpson, W. R.: Snow physics as relevant to snow photochemistry, Atmos. Chem. Phys., 8, 171-208, doi:10.5194/acp-8-171-2008, 2008.

Domine, F., Taillandier, A.-S., Cabanes, A., Douglas, T. A., and Sturm, M.: Three examples where the specific surface area of snow increased over time, The Cryosphere, 3, 31-39, doi:10.5194/tc-3-31-2009, 2009.

Domine, F., Gallet, J.-C., Bock, J., and Morin, S.: Structure, specific surface area and thermal conductivity of the snowpack around Barrow, Alaska, J. Geophys. Res., 117, D00R14, doi:10.1029/2011jd016647, 2012.
Dullien, F. A. L.: Porous media: fluid transport and pore structure, Academic Press, San Diego CA (USA), 1992.

Essery, R., Morin, S., Lejeune, Y., and Ménard, C. B.: A comparison of 1701 snow models using observations from an alpine site, Adv. Water Resour., 55, 131-148, doi:10.1016/j.advwatres.2012.07.013, 2013.

Fierz, C., Armstrong, R. L., Durand, Y., Etchevers, P., Greene, E., McClung, D. M., Nishimura, K., Satyawali, P. K., and Sokratov, S. A.: The International classification for seasonal snow on the ground, UNESCO-IHP, Paris, IACS Contribution No. 1, 80 pp., 2009.

Flanner, M. G. and Zender, C. S.: Linking snowpack microphysics and albedo evolution, J. Geophys. Res., 111, D12208, doi:10.1029/2005jd006834, 2006.

Freitag, J., Dobrindt, U., and Kipfstuhl, J.: A new method for predicting transport properties of polar firn with respect to gases on the pore-space scale, Ann. Glaciol., 35, 538-544, doi:10.3189/172756402781816582, 2002.

Gouttevin, I., Menegoz, M., Dominé, F., Krinner, G., Koven, C., Ciais, P., Tarnocai, C., and Boike, J.: How the insulating properties of snow affect soil carbon distribution in the continental pan-Arctic area, J. Geophys. Res., 117, G02020, doi:10.1029/2011jg001916, 2012.

Harder, S. L., Warren, S. G., Charlson, R. J., and Covert, D. S.: Filtering of air through snow as a mechanism for aerosol deposition to the Antarctic ice sheet, J. Geophys. Res., 101, 18729-18743, doi:10.1029/96jd01174, 1996.

Jacobi, H.-W., Domine, F., Simpson, W. R., Douglas, T. A., and Sturm, M.: Simulation of the specific surface area of snow using a one-dimensional physical snowpack model: implementation and evaluation for subarctic snow in Alaska, The Cryosphere, 4, 35-51, doi:10.5194/tc-4-35-2010, 2010.

Jordan, R. E., Hardy, J. P., Perron, F. E., and Fisk, D. J.: Air permeability and capillary rise as measures of the pore structure of snow: an experimental and theoretical study, Hydrol. Process., 13, 1733-1753, doi:10.1002/(SICI)10991085(199909)13:12/13<1733::AID-HYP863>3.0.CO;2-2, 1999.

Legagneux, L. and Domine, F.: A mean field model of the decrease of the specific surface area of dry snow during isothermal metamorphism, J. Geophys. Res., 110, F04011, doi:10.1029/2004jf000181, 2005.

Legrand, M. and Mayewski, P.: Glaciochemistry of polar ice cores: a review, Rev. Geophys., 35, 219-243, doi:10.1029/96rg03527, 1997.

Masson, V., Le Moigne, P., Martin, E., Faroux, S., Alias, A., Alkama, R., Belamari, S., Barbu, A., Boone, A., Bouyssel, F., Brousseau, P., Brun, E., Calvet, J.-C., Carrer, D., Decharme, B., Delire, C., Donier, S., Essaouini, K., Gibelin, A.-L., Giordani, H., Habets, F., Jidane, M., Kerdraon, G., Kourzeneva, E., Lafaysse, M., Lafont, S., Lebeaupin Brossier, C., Lemonsu, A., Mahfouf, J.-F., Marguinaud, P., Mokhtari, M., Morin, S., Pigeon, G., Salgado, R., Seity, Y., Taillefer, F., Tanguy, G., Tulet, P., Vincendon, B., Vionnet, V., and Voldoire, A.: The SURFEXv7.2 land and ocean surface platform for coupled or offline simulation of earth surface variables and fluxes, Geosci. Model Dev., 6, 929-960, doi:10.5194/gmd-6-929-2013, 2013.

Morin, S., Lejeune, Y., Lesaffre, B., Panel, J.-M., Poncet, D., David, P., and Sudul, M.: An 18-yr long (1993-2011) snow and meteorological dataset from a mid-altitude mountain site (Col de Porte, 
France, $1325 \mathrm{~m}$ alt.) for driving and evaluating snowpack models, Earth Syst. Sci. Data, 4, 13-21, doi:10.5194/essd-4-13-2012, 2012.

Morin, S., Domine, F., Dufour, A., Lejeune, Y., Lesaffre, B., Willemet, J. M., Carmagnola, C. M., and Jacobi, H. W.: Measurements and modeling of the vertical profile of specific surface area of an alpine snowpack, Adv. Water Resour., 55, 111-120, doi:10.1016/j.advwatres.2012.01.010, 2013.

Pinzer, B. R. and Schneebeli, M.: Snow metamorphism under alternating temperature gradients: morphology and recrystallization in surface snow, Geophys. Res. Lett., 36, L23503, doi:10.1029/2009g1039618, 2009.

Reimer, A.: The effect of wind on heat transfer in snow, Cold Reg. Sci. Technol., 3, 129-137, doi:10.1016/0165-232x(80)90017-8, 1980.

Shimizu, H.: Air permeability of deposited snow, Low Temp. Sci. Contrib. Ser. A, 22, 29-35, 1970.

Simpson, W. R., Alvarez-Aviles, L., Douglas, T. A., Sturm, M., and Domine, F.: Halogens in the coastal snow pack near Barrow, Alaska: evidence for active bromine air-snow chemistry during springtime, Geophys. Res. Lett., 32, L04811, doi:10.1029/2004g1021748, 2005.

Sokratov, S. A. and Sato, A.: Wind propagation to snow observed in laboratory, edited by: Steffen, K., Ann. Glaciol., 31, 427-433, 2000.

Sommerfeld, R. A. and LaChapelle, E.: The classification of snow metamorphism, J. Glaciol., 9, 3-17, 1970.

Sommerfeld, R. A. and Rocchio, J. E.: Permeability measurements on new and equitemperature snow, Water Resour. Res., 29, 2485-2490, 1993.
Spicer, C. W., Plastridge, R. A., Foster, K. L., Finlayson-Pitts, B. J., Bottenheim, J. W., Grannas, A. M., and Shepson, P. B.: Molecular halogens before and during ozone depletion events in the Arctic at polar sunrise: concentrations and sources, Atmos. Environ., 36, 2721-2731, 2002.

Sturm, M. and Benson, C. S.: Vapor transport, grain growth and depth-hoar development in the subarctic snow, J. Glaciol., 43, 42-59, 1997.

Taillandier, A. S., Domine, F., Simpson, W. R., Sturm, M., Douglas, T. A., and Severin, K.: Evolution of the snow area index of the subarctic snowpack in central Alaska over a whole season. Consequences for the air to snow transfer of pollutants, Environ. Sci. Technol., 40, 7521-7527, doi:10.1021/es060842j, 2006.

Taillandier, A. S., Domine, F., Simpson, W. R., Sturm, M., and Douglas, T. A.: Rate of decrease of the specific surface area of dry snow: isothermal and temperature gradient conditions, J. Geophys. Res., 112, F03003, doi:10.1029/2006jf000514, 2007.

Vionnet, V., Brun, E., Morin, S., Boone, A., Faroux, S., Le Moigne, P., Martin, E., and Willemet, J.-M.: The detailed snowpack scheme Crocus and its implementation in SURFEX v7.2, Geosci. Model Dev., 5, 773-791, doi:10.5194/gmd-5-773-2012, 2012.

Wever, N., Fierz, C., Mitterer, C., Hirashima, H., and Lehning, M.: Solving Richards Equation for snow improves snowpack meltwater runoff estimations, The Cryosphere Discuss., 7, 2373-2412, doi:10.5194/tcd-7-2373-2013, 2013. 